\title{
Integration of the Internet of Things in Service Management: Designing a Monitoring Device for the Elderly
}

\author{
F. F. Vilela, G. A. R. Toledo, R. F. Tomaz
}

\section{ABSTRACT}

Controlling and monitoring the elderly is an arduous and imperative task about their physical safety. To assist in this control above, the main objective of this project is to present a real prototype for monitoring the elderly. Therefore, this prototype can become a support tool for managers of nursing homes, hospitals, etc., as it enables more precise control of these older adults. The case study method was applied in this research through a qualitative exploratory approach. It was concluded that the prototype presented has great potential to assist the administration of care services for the elderly, whose importance is even greater in the current context of a growing number of older adults in the Brazilian population. Finally, it is expected that the real prototype, when in the future it is transformed into a technological product on the market, will be a plausible way to carry out the control of the elderly in an agile way. An increase in the physical safety of the elderly is also expected, as this device can reduce incidents of falls.

Keywords: Elderly, Internet of Things, Monitoring Device, Real Prototype, Service Management

Published Online: February 11, 2022

ISSN: $2736-660 \mathrm{X}$

DOI: 10.24018 /ejdevelop.2022.2.1.61

F. F. Vilela*

Applied Technology, MG, Brazil.

(e-mail: flaviofvilela ${ }^{\circledR}$ univas.edu.br)

G. A. R. Toledo

Applied Technology, MG, Brazil. (e-mail:

gabrielalmeida@fuvs.br)

R. F. Tomaz

Applied Technology, MG, Brazil.

(e-mail: rebecat ${ }^{\circledR}$ fuvs.br)

*Corresponding Author

\section{INTRODUCTION}

Service management needs robust tools to support it, as it is imperative that operations have to constantly work with a high level of efficiency (Slack et al., 2009). It is important to highlight that the advent of Industry 4.0 brought six innovative pillars: manufacturing process technology, materials, data, predictive engineering, sustainability and resource sharing (Kusiak, 2017). This last pillar must make an interface with the Internet of Things (IoT), which has the function of performing an agile intercommunication between several electronic devices, as well as between these and their users, through sensors and wireless connections (Ashton, 2009). This contextualization converges to a probable interface between service management and the IoT above. More specifically, in this article, service management will be more related to elderly care operations and the Industry 4.0 pillar that will be explored (resource sharing) concerns the intrinsic applications of the IoT. Given the above, this article aims to present a real prototype that will have the purpose of real-time monitoring of the elderly who need more intense supervision. This prototype will be operated by an ESP8266EX microcontroller, coupled to an ultrasonic sensor, which is installed in the doors or beds of elderly rooms will send a notification to an application installed on the nurse, caregiver, or family member responsible for supervising the dependent elderly. This notification will have the information of which room or bed the assistance worker should go to contain the elderly and prevent a probable accident, such as a fall, for example, which can bring severe consequences (Konrad et al., 1999).

\section{LITERATURE REVIEW}

\section{A. Aging of the Brazilian population}

In recent decades, the aging of the world population has been marked by an increase in life expectancy and a reduction in birth and mortality rates in most countries. Thus, it was found an increase in the number of older adults over 80 years old. Therefore, Brazil surpassed the mark of 30 million older adults and reached $14 \%$ of the total population, with people aged 80 years or more (Ceccon et al., 2021). In this advanced stage of age, the elderly is vulnerable from a social and physical and mental health point of view, with loss of autonomy and increased dependence being common (Freedman \& Nicolle, 2020). It is also important to emphasize that there is a small portion of older adults over 80 years old without their own income and who cannot meet their basic needs, in addition to experiencing the serious health problems and physical and mental dependencies mentioned previously (Minayo, 2012). 


\section{B. Causes and consequences of elderly falls}

According to the authors Coelho Fabrício et al. (2004), people of all ages are at risk of falling. However, for the elderly, they have a very relevant meaning, as they can lead to disability, injury and death. Studies carried out in the USA show that $30 \%$ of people over the age of 65 fall at least once a year, and $40 \%$ of them are over 80 years old. Furthermore, these studies show that $50 \%$ of older adults who live in nursing homes or nursing homes have already suffered a fall (Kannus et al., 1999). Statistical information indicates that fractures resulting from falls are responsible for approximately $70 \%$ of accidental deaths in people over 75 years, with the elderly having ten times more hospitalizations and eight times more deaths resulting from these falls (Konrad et al., 1999).

\section{Internet of things}

The term Internet of Things (IoT) was first introduced by Kevin Ashton in 1999 to manage a supply chain (Ashton, 2009). However, in the last decade, the definition has become more general, covering different application possibilities such as health, public services, security, etc. (Sundmaeker, 2010). Although the primary definition of "Things" has gained other semantics with the evolution of technology, the main objective of making a computer detect information without the aid of human intervention remains unchanged. In this context, an exponential evolution of the "Internet" into an interconnected network that collects information from the environment, interacts with the physical world (action, command, control) and uses existing standards to provide analytics, applications and communications services was observed. Using information from devices enabled by open wireless technology (Bluetooth, Wi-Fi) as well as embedded sensors, the Internet of Things has emerged from an incipient initial stage and is on the verge of transforming the current static internet into a fully integrated and future internet of the future accessible (Buckley, 2006).

\section{RESEARCH MethodOLOGY}

This article has an applied nature, as its results have as its main function to solve some of the problems in the real world (Turrioni \& Mello, 2012). In the context of this research, the problem is about the efficient real-time monitoring of older adults. The applied nature seeks to generate essential knowledge and information to solve the problem of a real system that has, in this way, local truths and interests (Gil, 2002). Analyzing the historical data in the previously presented section "Aging of the Brazilian population" it is evident that the interests are also at the national level. As for the objectives, it can be said that the research is classified as exploratory, as it aims at discovering, finding, elucidating phenomena or explaining those that were not accepted despite being evident. Due to this exploratory character, a new product (electronic prototype) was conceived by creative impulse when the researchers were in field research. Finally, regarding the approach to the problem, the research is classified as qualitative, because in a real system analyzed, the case study method was applied.

\section{Method DeVelopment And APplication}

\section{A. Application context}

The purpose of this real prototype is to present healthcare service managers with a device for monitoring elderly patients, whether in a hospital, residential or nursing home environment. The device has the function of notifying, through cell phone message, the nurse, caregiver, or family member when the patient leaves their room or confinement area without proper monitoring. As shown Fig.1, the device can be installed, for example, close to an older adult's bedroom door, either at home or in a hospital environment.

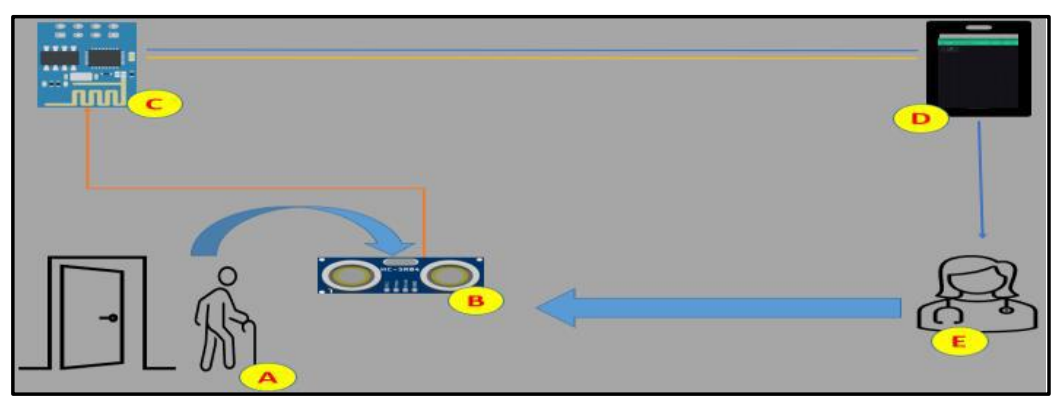

Fig.1. Elderly monitoring overview. 
As soon as the latter leaves this room, the ultrasonic sensor recognizes the obstacle and immediately informs the person responsible, through cell phone messages, about the undue movement of the monitored person. Also in this Fig.1, there is the following correspondence of the "letters": A - elderly, B - ultrasonic sensor, C - ESP8266, D - application running on a smartphone, E - nurse or family member.

\section{B. Technical detail}

The system is made up of hardware and software, with the ESP8266 being the main component of the hardware set. From a software perspective, the system was developed in HTML5 and CSS, as this way an easy-to-understand "front-end" interface was created and executed. Therefore, the end user (caregiver) will receive the evasion message from the elderly person on their mobile device in an agile and reliable way. After developing of the virtual prototype and programming of the elderly monitoring device, it was possible to carry out the physical assembly of the project. The following is presented (Fig.2) how the real prototype looked, relative to its physical appearance. It is important to mention that the protection "case" was specifically designed in Autocad® to be used in this project.

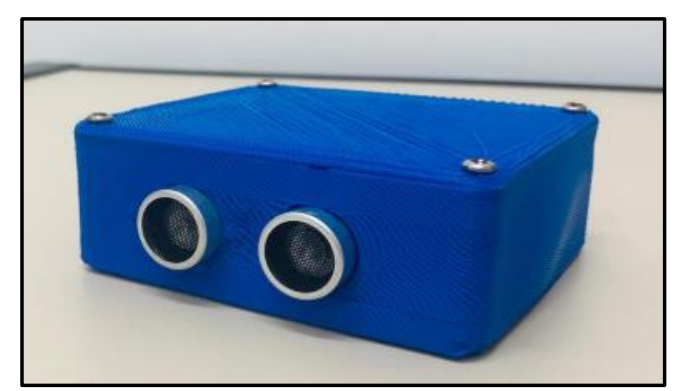

Fig. 2. Real prototype for monitoring the elderly.

The ESP8266 Module (Fig.3) is an open-source prototyping platform designed with a dynamic and intuitive interface. This module has a small size, and its cost is reasonably small compared to others, which have the capability of WiFi connectivity, in which it has an $802.11 \mathrm{~b} / \mathrm{g} / \mathrm{n} / \mathrm{e} / \mathrm{i}$ communication protocol, which allows a signal range up to 120 meters in an open place (Škraba et al., 2016).

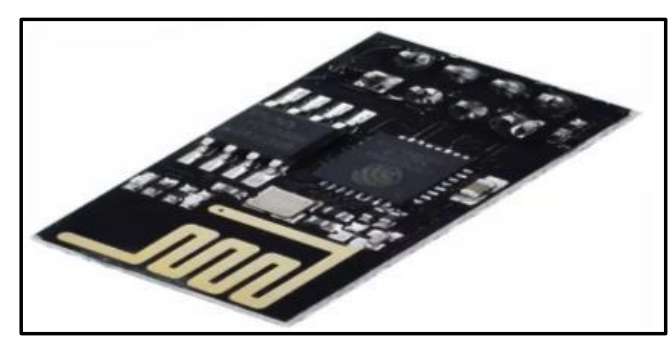

Fig. 3. Photo of the "protagonist" of the proposed device.

\section{Materials and costs}

Table 1 lists all components and their amounts that were used in the device above. The average price of each component is also shown in this table and shows that the costs are low at the expense of the device's application potential.

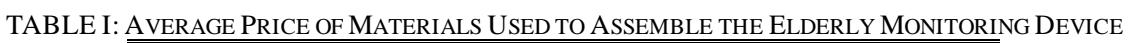

\begin{tabular}{lcc}
\hline \hline \multicolumn{1}{c}{ Component } & Quantity & Average price (\$) \\
\hline ESP8266 & 1 & 7 \\
LM2596 voltage regulator & 1 & 3.5 \\
Ultrasonic sensor & 1 & 4 \\
Seesaw key & 1 & 3.5 \\
DC power connector P4 & 1 & 0.5 \\
9v source & 1 & 3.5 \\
Protection box (case) & 1 & 3 \\
Total & & 25 \\
\hline \hline
\end{tabular}




\section{ConCLusion}

The increase in life expectancy of the Brazilian population, consequently, implies a growing number of older adults in the country. This fact determines the emergence of new welfare demands that must be properly supplied and satisfied. Technologies that supplement stewardship and security actions within this context will have significant value to senior care administrators. For this reason, the actual prototype presented emerges as a relevant IoT technology. About the present article conceived, it can be said that the proposed objective was satisfactorily achieved, as the real prototype for monitoring the elderly was presented in detail. In addition, it is essential to emphasize again the importance of the proposed IoT technology, as it quickly warns employees of nursing homes, hospitals, etc. that monitored older adults are "leaving" their rooms without due care, enabling actions that prevent possible accidents, can be taken. Therefore, this technology enables greater control, monitoring and care for the elderly. Finally, this present work showed all the components used and their respective costs, making it clear that the low cost required for assembling the device will imply a market technological solution accessible to service managers, as soon as it is opportunely launched.

\section{ACKNOWLEDGMENT}

The authors of this research would like to thank the Fundação de Ensino do Vale do Sapucaí (FUVS) for all the support and encouragement to the research.

\section{CONFLICT OF INTEREST}

Authors declare that they do not have any conflict of interest.

\section{REFERENCES}

Ashton, K. (2009). That 'internet of things' thing. RFID journal, 22(7), 97-114.

Buckley, J. (2006). The internet of things: from RFID to the next-generation pervasive networked systems. New York: Auerbach.

Ceccon, R. F., et al. (2021). Aging and dependence in Brazil: sociodemographic and care characteristics of older adults and caregivers. Ciência \& Saúde Coletiva, 26, 17-26.

Fabrício, S. C. C., Rodrigues, R. A. P., \& Costa Junior, M. L. D. (2004). Causas e consequiências de quedas de idosos atendidos em hospital público. Revista de saúde Pública, 38, 93-99.

Freedman, A., \& Nicolle, J. (2020). Social isolation and loneliness: The new geriatric giants: Approach for primary care. Canadian Family Physician, 66(3), 176-182.

Gil, A. C. (2002). Como elaborar projetos de pesquisa. São Paulo: Atlas, 1993.

Kannus, P., et al. (1999). Fall-induced injuries and deaths among older adults. Jama, 281(20), 1895-1899.

Konrad, H. R., Girardi, M., \& Helfert, R. (1999). Balance and aging. The Laryngoscope, 109(9), 1454-1460.

Kusiak, A. (2018). Smart manufacturing. International Journal of Production Research, 56(1-2), 508-517.

Minayo, M. C. D. S. (2012). O envelhecimento da população brasileira e os desafios para o setor saúde. Cadernos de Saúde Pública, 28, 208-210. Brazil.

Škraba, A., Koložvari, A., Kofjač, D., Stojanović, R., Stanovov, V., \& Semenkin, E. (2016, June). Streaming pulse data to the cloud with bluetooth LE or NODEMCU ESP8266. In 2016 5th Mediterranean Conference on Embedded Computing (MECO) (pp. 428-431). IEEE.

Slack, N., Chambers, S., \& Johnston, R. (2009). Administração da produção (Vol. 2). São Paulo: Atlas.

Sundmaeker, H., Guillemin, P., Friess, P., \& Woelfflé, S. (2010). Vision and challenges for realising the Internet of Things. Cluster of European research projects on the internet of things, European Commision, 3(3), 34-36.

Turrioni, J. B., \& Mello, C. H. P. (2012). Metodologia de pesquisa em engenharia de produção: estratégias, métodos e técnicas para condução de pesquisas quantitativas e qualitativas. Itajubá: Unifei.

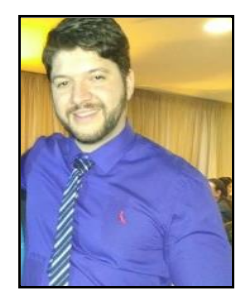

F. F. Vilela is Ph.D candidate in Technologies 4.0 at the Federal University of Itajubá. Master in Computer Simulation from the Federal University of Itajubá (2015). He is currently Research Coordinator at the University of Vale do Sapucaí, Coordinator of the Hospital Technology Center at Hospital das Clínicas Samuel Libânio and professor of undergraduate courses in Production Engineering, Industrial Production Management Technology and Administration at the University of Vale do Sapucaí (UNIVAS). Its main areas of expertise are: HealthCare 4.0, Computer Simulation, Virtual Reality, Artificial Intelligence and IoT. $\mathrm{He}$ also has several software and patents registered. His objective is to incorporate cutting edge technologies in hospital processes, bringing innov ation, development and cost reduction. More details about your research at: http://lattes.cnpq.br/8745354624285353. 
European Journal of Development Studies www.ej-develop.org

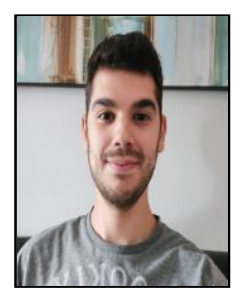

G. A. R. Toledo is Industrial engineer. He is currently a Process Assistant at the Vale do Sapucaí Higher Education Foundation and developer of mobile and web applications. Its main activities are the mapping of sectors, with the preparation of POP's, seeking to identify through these the possibility of implementing technologies for process optimization. More details at: https://www.linkedin.com/in/gabriel-toledo50a08a188/

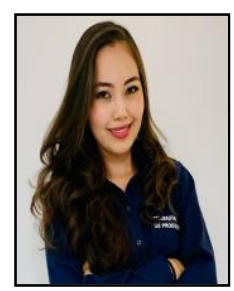

R. F. Tomaz is Industrial Engineer graduated from the University of Vale do Sapucaí located in Pouso Alegre - MG, Brazil. Currently administrative assistant at the Vale do Sapucaí Higher Education Foundation, working in the Compliance and Governance sector. Responsible for assisting with accountability, company bidding and project monitoring. 